\title{
ЭТИОЛОГИЯ И ОСОБЕННОСТИ ТЕЧЕНИЯ ХБП У ДЕТЕЙ ПРИ ПАТОЛОГИИ МОЧЕВЫДЕЛИТЕЛЬНОЙ СИСТЕМЫ
}

\author{
Никитенко О. П., Кандидат медичинских наук, ассистент кафедры педиатрии №2, Одесский \\ национальный медицинский университет, г. Одесса, Украина, \\ ORCID ID: https://orcid.org/0000-0002-1608-2536 \\ Стоева Т. В., Доктор медицинских наук, профессор, заведущий кафедры педиатрии №2, \\ Одесский национальный медищинский университет, г. Одесса, Украина, \\ ORCID ID: https://orcid.org/0000-0003-0372-1498 \\ Федин М. В., Кандидат медицинских наук, ассистент кафедры педиатрии №2, Одесский \\ национальный медицинский университет, г. Одесса, Украина, \\ ORCID ID: https://orcid.org/0000-0002-1219-8398 \\ Гоженко А. И., Доктор медииинских наук, профессор, директор НИИ медицины транспорта \\ M3 Украиньl, г. Одесса, Украина, ORCID ID: https://orcid.org/0000-0001-7413-4173 \\ DOI: https://doi.org/10.31435/rsglobal_conf/28022021/7434
}

Abstract. This article presents data on the development of (chronic kidney disease) CKD in children. In particular, with the pathology of the urinary system in children of different age groups. We analyzed the main clinical characteristics and laboratory parameters in children with pathology of the urinary system. The main parameters of the functional state of the kidneys were considered, the glomerular filtration rate (GFR) was calculated using the CKD EPI formula. The chronic pathology of the urinary system in children was also analyzed. The course of CKD in children with various clinical nosological forms of kidney pathology was studied.

Keywords: chronic kidney disease, urinary system, children, glomerular filtration rate, UTI.

Введение. В настоящее время заболеваемость органов мочевыделительной системы (MBC) у детей остается актуальной. В мире ежегодно увеличивается нефрологическая патология у детей. Согласно данным многих популяционных исследований отмечается значительное увеличение числа пациентов с заболеваниями органов МВС. Особенно высокие темпы роста обнаруживают врожденные пороки развития почек и дисметаболические нефропатии, что приводит к изменению структуры патологии. К примеру, только в России показатель общей распространенности заболеваний органов МВС у детей за последние два десятилетия увеличился на $74,5 \%(\mathrm{p}<0,0001)[1,2]$.

Общеизвестно, что в педиатрии термин «хроническая болезнь почек» (ХБП) впервые применил R.J. Hogg в 2003 г. идентично используемому термину в терапевтической практике у взрослых пациентов и в настоящее время определение и классификация ХБП по стадиям у детей не отличаются от таковых у взрослых, и широко используется в детской клинике и при проведении научных исследований [3,4]. Однако течение ХБП у детей имеет свои отличительные особенности, которые проявляются воздействием на рост ребенка, на нейрогуморальную и вегетативную систему, психологическое воздействие на семью в целом и наличием осложнений со стороны сердечно-сосудистой системы [4,5].

Исходя из данных национальных регистров, за последнее десятилетие нарушение фильтрационной способности почек на 1 млн. детского населения диагностируется в $18,5-58,3$ случаях, а средняя заболеваемость терминальной хронической почечной недостаточностью $(\mathrm{XПН)} \mathrm{у} \mathrm{детей} \mathrm{до} 16$ лет составляет $1-3$ новых случая в год на 1 млн. общего населения. В Европе распространенность терминальной ХПН у детей составляет 4-6 случаев на 1 млн. детского населения в год, в США - 11 случаев и в России - 4-5 случаев на 1 млн. детского населения в год [6-8].

По данным регистра European Renal Association - European Dialysis and Transplant Association (ERA-EDTA), установлено, что ежегодная заболеваемость терминальной ХПН в Европе составляла 7,1 на 1 млн. детей в 1980-1984 гг. и 9,9 - в последующие 15 лет [9].

Развитие терминальной ХПН также зависит и от возраста ребенка: среди детей 15-18 лет ее распространенность вдвое выше, чем в возрастной группе 10-14 лет, и почти в 3 раза выше, чем среди детей с рождения до 5 лет. Согласно данным Японского национального 
реестра и реестра Австралии и Новой Зеландии по диализу и трансплантации (ANZDATA), ежегодная заболеваемость терминальной ХПН равна 22 на 1 млн. детского населения, у детей коренного населения риск его возникновения значительно выше, чем у остального детского населения [10,11].

Особенностью ХБП у детей является также то, что даже на ранних ее стадиях при отсутствии лечения с высокой вероятностью приводит к терминальной ХПН. Что, в свою очередь, должно учитываться при составлении диагностических и терапевтических подходов к ХБП с направленностью на раннее обнаружение, предупреждение и активное лечение всех нефропатий с целью предотвращения развития терминальной ХПН [4].

Таким образом, целью нашего исследования было охарактеризовать клиниколабораторную характеристику и проанализировать хроническую патологию мочевыделительной системы у детей.

\section{Методы исследования.}

В исследовании приняли участие 288 пациентов, находившихся на стационарном лечении в Городской детской больнице им. академика Б.Я. Резника г. Одессы. Проводилось ретроспективное исследование историй болезни стационарных пациентов детей нефрологического отделения в возрасте от 1 года до 18 лет, за период обращения за медицинской помощью с 1 декабря 2016 года по 1 августа 2018 гг.

При анализе клинического материала учитывали анамнез заболевания, клинический диагноз, осложнения, сопутствующие заболевания, данные общего и биохимического анализ крови, общий анализ мочи, проба Зимницкого, Нечипоренко, бактериологическое исследование мочи, Rg-урологическое исследование.

Все пациенты получали лечение согласно Международным Европейским рекомендациям.

Статистический анализ выполняли с помощью программы Statistica (StatSoft, Inc. (2001) STATISTICA (data analysis software system), version6. Www.statsoft.com). Достоверность качественных показателей определялась по $\chi 2$-критерию Пирсона.

Критерии включения в исследование: врожденные аномалии почек и мочевыводящих путей; острые и хронические заболевания почек; инфекции мочевыводящих путей; возраст моложе 18 лет.

При классифицировании ХБП по стадиям были использованы Clinical Practice Guidelines of the National Kidney Foundation's Kidney Disease Outcomes Quality Initiative (KDOQI guidelines) [12].

\section{Результаты исследования.}

Общая характеристика изучаемой группы пациентов была следующей: средний возраст обследованных детей составил 8,62 $\pm 0,7$ года. Мальчиков было 69 человек $(24,0 \%)$, девочек 219 (76,0 \%) детей, соотношение составило 1:3,17 (табл.1). Средние показатели роста и веса детей при рождении составили $51,86 \pm 0,38$ см. и, соответственно, $3305,25 \pm 83,63$ кг, в среднем гистационном сроке $39,27 \pm 0,26$ недель.

По клиническим нозоформам у детей отмечали следующие: инфекция мочевыводящих путей (ИМВП) (142 человека - 49,31 \%), хронический пиелонефрит (45 чел. - 15,63\%), хронический цистит $(37-12,85 \%)$, острый цистит $(10-3,47 \%)$, острый пиелонефрит $(28-9,72 \%)$, пузырно-мочеточниковый рефлюкс (ПМР) $(18$ - 6,23\%), острый гломерулонефрит $(4-1,39 \%)$, хронический гломерулонефрит $(2-0,69 \%)$, нейрогенный мочевой пузырь $(12-4,17)$, нефропатия с изолированным мочевым синдромом $(1-0,35 \%)$, дисметаболическая нефропатия $(18-6,23 \%)$, мочекаменная болезнь (МКБ) (7 - 2,43\%), кристаллурия (гиперурикозурия) (5 - 1,74\%), интерстициальный нефрит $(0,35 \%)$. ВАРМС: агенезия левой почки $(0,35 \%)$, ротация правой почки $(0,35 \%)$, поликистоз почек $(4-1,39 \%)$, подковообразная почка, неполное удвоение правой половины почки $(0,35 \%)$, неполное удвоение ЧЛС слева $(0,35 \%)$, удвоение левой почки и мочеточника $(2-0,69 \%)$, экстрофия мочевого пузыря $(0,35 \%)$, дивертикулы мочевого пузыря $(0,35 \%)$, левосторонний уретерогидронефроз $(3-1,04 \%)$, правосторонний уретерогидронефроз (2 $0,69 \%)$, двусторонний уретерогидронефроз $(0,35 \%)$, пиелоэктазия справа $(3-1,04 \%)$, пиелоэктазия слева $(0,35 \%)$, пиелоэктазия обеих почек $(0,35 \%)$, повышенная подвижность правой почки $(0,35 \%)$, аплазия левой почки $(0,35 \%)$, гипотония лоханок обеих почек $(2-0,69 \%)$, спинальный мочевой пузырь $(4-1,39 \%)$ подвздошная дистопия правой почки $(0,35 \%)$, гипоплазия правой почки $(0,35 \%)$, 
единственная почка $(0,35 \%)$. Соответственно, по стадиям ХБП пациенты распределялись следующим образом: ХБП 1 ст. - 19 (6,6\%), ХБП 2 ст. - 136 (47,22\%), ХБП 3 ст. - 68 (23,61\%), ХБП 4 ст $(3-1,04 \%)$, ХПН 5 ст. $(1,04 \%)$.

Состояние пациентов при поступлении в отделение стационара было следующее: удовлетворительное - 55 человек $(19,1 \%)$, средней степени тяжести - 212 (73,61\%), тяжелое 21 пациент (7,29\%). Дизурические явления отмечались у 78 детей $(27,08 \%)$ и боли в пояснице у 83 человек $(28,82 \%)$. Симптом Пастернацкого справа положительным был у 76 пациентов $(26,39 \%)$ и слева - у $79(27,43 \%)$.

Таблица 1. Распределение детей по возрасту и полу

\begin{tabular}{|c|c|c|c|c|c|c|}
\hline \multirow[t]{2}{*}{ Возраст } & \multicolumn{3}{|c|}{ Мальчики } & \multicolumn{3}{|c|}{ Девочки } \\
\hline & $\begin{array}{c}\text { Количество } \\
\text { детей }\end{array}$ & $\begin{array}{c}\% \text { в } \\
\text { группе } \\
\text { мальчиков }\end{array}$ & $\begin{array}{c}\% \text { от } \\
\text { общего } \\
\text { количества } \\
\text { детей } \\
\end{array}$ & $\begin{array}{c}\text { Количество } \\
\text { детей }\end{array}$ & $\begin{array}{c}\% \text { в } \\
\text { группе } \\
\text { девочек }\end{array}$ & $\begin{array}{c}\text { \% от } \\
\text { общего } \\
\text { количества } \\
\text { детей } \\
\end{array}$ \\
\hline $\begin{array}{l}\text { Ранний возраст } \\
\text { (с } 1 \text { года до } \\
3 \text { лет) }\end{array}$ & 10 & 14,49 & 3,47 & 38 & 17,35 & 13,19 \\
\hline $\begin{array}{l}\text { Дошкольный } \\
\text { возраст } \\
\text { (с } 3 \text { до } 7 \text { лет) }\end{array}$ & 10 & 14,49 & 3,47 & 67 & 30,59 & 23,27 \\
\hline $\begin{array}{l}\text { Младший } \\
\text { школьный } \\
\text { возраст } \\
\text { (c } 7 \text { до } 11 \text { лет) }\end{array}$ & 15 & 21,74 & 5,21 & 39 & 17,81 & 13,54 \\
\hline $\begin{array}{l}\text { Средний } \\
\text { школьный } \\
\text { возраст } \\
\text { (с } 11 \text { до } 15 \text { лет) }\end{array}$ & 21 & 30,43 & 7,3 & 33 & 15,07 & 11,46 \\
\hline $\begin{array}{l}\text { Старший } \\
\text { школьный } \\
\text { возраст } \\
\text { (с } 15 \text { до } 18 \text { лет) }\end{array}$ & 13 & 18,85 & 4,51 & 42 & 19,18 & 14,58 \\
\hline
\end{tabular}

Для характеристики функционального состояния почек рассчитали скорость клубочковой фильтрации (СКФ) по формуле CKD ЕРІ. Средние показатели СКФ составили

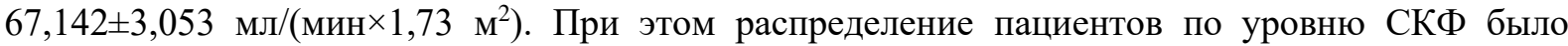
следующее: от 6 до 20 мл/(мин $\times 1,73$ м $\left.^{2}\right)$ было 3 пациента, что составило 1,04\%, от 20 до 50 мл/(мин $\times 1,73$ м $\left.^{2}\right)-52$ ребенка $(18,06 \%)$, от 50 до 60 мл/(мин $\times 1,73$ м $\left.^{2}\right)$ было 46 человек $(15,97 \%)$, от 60 до 90 мл/(мин $\times 1,73$ м $\left.^{2}\right)-161$ человек $(55,9 \%)$, от 90 до 125 мл/(мин $\times 1,73$ м $\left.^{2}\right)-$ 24 больных $(8,33 \%)$ и выше 125 мл/(мин×1,73 м²) - $2(0,69 \%)$.

Таблица 2. Показатели общего анали за крови у детей

\begin{tabular}{|l|c|}
\hline \multicolumn{1}{|c|}{ Показатель } & $\mathbf{M} \pm \mathbf{m}$ \\
\hline Эритроциты, $1 \times 10^{12} /$ л & $4,05 \pm 0,06$ \\
\hline Гемоглобин, г/л & $124,99 \pm 2,58$ \\
\hline ЦП & $0,93 \pm 0,01$ \\
\hline Лейкоциты, $1 \times 10^{9} /$ л & $6,57 \pm 3,21$ \\
\hline Тромбоциты, $1 \times 10^{9} /$ л & $7,21 \pm 0,51$ \\
\hline СОЭ, мм/ч & $14,94 \pm 1,63$ \\
\hline
\end{tabular}

Примечание: $\mathrm{p} \geq 0,01$.

Также мы проанализировали изменения общего анализа крови (табл.2) у детей и некоторых биохимических показателей крови (табл. 3). 
Таблица 3. Показатели биохимического анализа крови у детей

\begin{tabular}{|l|c|}
\hline \multicolumn{1}{|c|}{ Показатель } & $\boldsymbol{M} \pm \boldsymbol{m}$ \\
\hline Билирубин общий, мкмоль/л & $13,97 \pm 1,28$ \\
\hline Мочевина, ммоль/л & $4,23 \pm 0,31$ \\
\hline Креатинин, мкмоль/л & $81,93 \pm 3,15$ \\
\hline Тимоловая проба & $1,96 \pm 0,08$ \\
\hline АлАТ, ммоль/ч×л & $0,72 \pm 0,33$ \\
\hline АсАТ, ммоль/ч×л & $0,92 \pm 0,49$ \\
\hline Глюкоза, ммоль/л & $4,10 \pm 0,10$ \\
\hline Альбумин, Г/л & $60,42 \pm 1,04$ \\
\hline Общий белок, Г/л & $69,85 \pm 1,55$ \\
\hline Мочевая кислота, ммоль/л & $356,14 \pm 18,33$ \\
\hline Холестерин, ммоль/л & $3,64 \pm 0,10$ \\
\hline Натрий, ммоль/л & $143,00 \pm 0,41$ \\
\hline Калий, ммоль/л & $4,31 \pm 0,22$ \\
\hline
\end{tabular}

Примечание: $\mathrm{p} \geq 0,01$.

Согласно данным уровня гемоглобина крови анемия была определена у 44 пациентов $(15,28 \%)$, по степени тяжести отмечали легкую - 41 ребенок, что составило $14,24 \%$ от общего количества пациентов, и средней степени тяжести - 3 детей $(1,04 \%)$. Число пациентов с анемией в разных возрастных группах было неравномерным, соотношение мальчики и девочки составило 1:3,4 (табл. 4). Коэффициент корреляции Пирсона между уровнем гемоглобина и возрастом детей составил 0,39 .

Таблица 4. Распределение детей по степени тяжести анемии согласно возрасту.

\begin{tabular}{|c|c|c|c|c|}
\hline \multirow[t]{2}{*}{ Возраст } & \multicolumn{2}{|c|}{$\begin{array}{c}\text { Легкая степень тяжести, } \\
\text { Нв } 110-90 \text { г/л }\end{array}$} & \multicolumn{2}{|c|}{$\begin{array}{c}\text { Средняя степень тяжести, } \\
\text { Нв 90-70 г/л }\end{array}$} \\
\hline & $\begin{array}{l}\text { Мальчики, чел. } \\
\text { (\% от общего } \\
\text { количества } \\
\text { детей; \% в } \\
\text { группе детей с } \\
\text { анемией) }\end{array}$ & $\begin{array}{c}\text { Девочки, чел. } \\
\text { (\% от общего } \\
\text { количества детей; } \\
\text { \% в группе детей с } \\
\text { анемией) }\end{array}$ & $\begin{array}{c}\text { Мальчики, чел. } \\
\text { (\% от общего } \\
\text { количества детей; } \\
\text { \% в группе детей } \\
\text { с анемией) }\end{array}$ & $\begin{array}{c}\text { Девочки, чел. } \\
\text { (\% от общего } \\
\text { количества детей; } \\
\text { \% в группе детей } \\
\text { с анемией) }\end{array}$ \\
\hline $\begin{array}{l}\text { Ранний возраст } \\
\text { (с } 1 \text { года до } 3 \text { лет) }\end{array}$ & $\begin{array}{c}5 \\
(1,74 ; 11,36) \\
\end{array}$ & $\begin{array}{c}12 \\
(4,17 ; 27,27) \\
\end{array}$ & $\begin{array}{c}1 \\
(0,35 ; 2,27)\end{array}$ & $\begin{array}{c}1 \\
(0,35 ; 2,27)\end{array}$ \\
\hline $\begin{array}{l}\text { Дошкольный } \\
\text { возраст } \\
\text { (с } 3 \text { до } 7 \text { лет) }\end{array}$ & 0 & $\begin{array}{c}16 \\
(5,55 ; 36,36)\end{array}$ & $\begin{array}{c}1 \\
(0,35 ; 2,27)\end{array}$ & 0 \\
\hline $\begin{array}{l}\text { Младший } \\
\text { школьный возраст } \\
\text { (с } 7 \text { до } 11 \text { лет) }\end{array}$ & $\begin{array}{c}3 \\
(1,04 ; 6,82)\end{array}$ & $\begin{array}{c}2 \\
(0,69 ; 4,55)\end{array}$ & 0 & 0 \\
\hline $\begin{array}{l}\text { Средний } \\
\text { школьный возраст } \\
\text { (с } 11 \text { до } 15 \text { лет) }\end{array}$ & 0 & $\begin{array}{c}1 \\
(0,35 ; 2,27)\end{array}$ & 0 & 0 \\
\hline $\begin{array}{l}\text { Старший } \\
\text { школьный возраст } \\
\text { (с } 15 \text { до } 18 \text { лет) }\end{array}$ & 0 & $\begin{array}{c}2 \\
(0,69 ; 4,55)\end{array}$ & 0 & 0 \\
\hline
\end{tabular}

Обострение инфекции верхних мочевых путей сопровождались гипертермией свыше $37,5^{\circ} \mathrm{C}(40,97 \%)$, ухудшением общего состояния $(84,72 \%)$, болью в поясничной области $(28,82 \%)$ и мочевым синдромом (100\%). Рецидивы инфекции нижних мочевых путей характеризовались наличием дизурических явлений $(27,08 \%)$ и изменений мочевого осадка $(100 \%)$.

В период обострения у обследованных детей определялась значимая лейкоцитурия $(79,86 \%)$, микропротеинурия $(40,28 \%)$, микрогематурия $(25,0 \%)$. В тоже время у $23,26 \%$ пациентов, независимо от периода заболевания, количество лейкоцитов при микроскопии мочи 
не превышало 10/мм³. Коэффициент корреляции Пирсона $(\boldsymbol{r})$ в анализе мочи по Нечипоренко между уровнем лейкоцитов и эритроцитов составил $0,34(\chi 2=0,12)$. При анализе пробы мочи по Зимницкому $\boldsymbol{r}$-Пирсона между ночным и дневным диурезом составил $0,56(\chi 2=0,31)$, между дневным и общим диурезом $-0,89(\chi 2=0,8)$ и ночным и общим диурезом $0,88(\chi 2=0,78)$.

По данным ретроспективного анализа было установлено, что все дети в анамнезе получали противорецидивную терапию ИМВП: антибиотикотерапия $(86,81 \%)$, уросептики $(93,75 \%)$, фитотерапия $(68,75 \%)$. При этом средняя частота рецидивов ИМВП составила $(3,45 \pm 0,51)$ эпизодов в год.

При микробиологическом исследовании мочи в структуре уропатогенов наиболее часто определяли E.coli - в 65,97\% случаев. Значительно реже выделяли представителей родов Proteus $(6,25 \%)$, Enterobacter (6,25\%). В спектре граммотрицательных бактерий также была выделена Pseudomonas aeruginosa (5,00\%). Среди граммположительных микроорганизмов наиболее часто выявляли Enterococcus (12,15\%), Staphylococcus $(5,00 \%)$.

При определении микробного числа в пробах мочи установлена степень бактериурии $\geq$ $10^{5} \mathrm{KOE}-$ у $65,97 \%, 10^{3}-10^{4}-$ у $30,20 \%$ и $<10^{3}-$ у $5,00 \%$ ) детей.

Выводы. Наиболее частыми клиническими нозоформами с хроническим течением у детей отмечались ИМВП $(49,31 \%)$, хронический пиелонефрит $(15,63 \%)$ и хронический цистит $(12,85 \%)$. Соотношение мальчиков и девочек составило $1: 3,17$. Также в группе мальчиков чаще отмечался средний школьный возраст $(30,43 \%)$, а в группе девочек - дошкольный возраст $(30,59 \%)$. Обострение ИМВП сопровождались гипертермией свыше $37,5^{\circ} \mathrm{C}(40,97 \%)$, изменением общего состояния $(84,72 \%)$, болью в поясничной области $(28,82 \%)$ и мочевым синдромом $(100 \%)$. Рецидивы характеризовались наличием дизурических явлений $(27,08 \%)$ и изменением мочевого осадка $(100 \%)$. Средняя частота рецидивов ИМВП составила $(3,45 \pm 0,51)$ эпизодов в год.

Таким образом, анализируя полученные нами данные мы можем прийти к выводу, что течение ХБП у детей при разных клинических нозоформах патологии почек сопровождаются в $100 \%$ случаев мочевым синдромом, при чем, в период обострения ИМВП у обследованных детей определялась значимая лейкоцитурия (79,86\%) и микропротеинурия $(40,28 \%)$, у $23,26 \%$ детей, независимо от периода заболевания, количество лейкоцитов при микроскопии мочи не превышало 10/мм ${ }^{3}$, что подтверждает факт недостаточной реактивности локального иммунного ответа у детей.

\section{REFERENCES}

1. Ivanov DD. Urinary tract infections: guidelines and clinical practice. Zdorov'ja Ukrai'ny. Pediatrija. 2017;3(42):27. (in Ukrainian).

2. Pukhova T.G., Spivak E.M., Leontyev I.A. Epidemiology of urinary tract diseases in children living in a large industrial city. Ros Vestn Perinatol i Pediatr 2016; 61: 6: 89-91 (in Russ). DOI: 10.21508/10274065-2016-61-6-89-91

3. Hogg RJ, Furth S, Lemley KV, et al. National Kidney Foundation's Kidney Disease Outcomes Quality Initiative clinical practice guidelines for chronic kidney disease in children and adolescents: evaluation, classification, and stratification. Pediatrics. 2003 Jun;111(6 Pt 1):1416-21. PMID: 12777562.

4. Каримджанов И.А., Исраилова Н.А. Хроническая болезнь почек у детей (обзор литературы). Zdorov'ye Rebenka. 2017;12(7):832-840. doi: 10.22141/2224-0551.12.7.2017.116190

5. Vivante A, Hildebrandt F. Exploring the genetic basis of earlyonset chronic kidney disease. Nat Rev Nephrol. 2016 Mar;12(3):133-46. doi: 10.1038/nrneph.2015.205.

6. ESPN/ERA-EDTA Registry (2010). ESPN/ERA-EDTA 5. registry annual report 2008. - URL: http://www.espn-reg.org/

7. Epidemiology of chronic kidney disease in children / 6. J. Harambat, K.J van Stralen, J.J. Kim, E.J. Tizard // Pediatr. Nephrol. — 2012. - Vol. 27. - P.363-373.

8. Даминова, М.А. Хроническая болезнь почек у детей: этиология, классификация и факторы прогрессирования / М.А. Даминова // Вестник современной клинической медицины. - 2016. - Т. 9, вып. 2. - С.36-41.

9. Cannata-Andia J, Zoccali C, Wanner C, at ERA-EDTA Work Group . ERA-EDTA Registry 2004 Annual Report. Amsterdam: Academic Medical Center; 2006. 117 p.

10. Dialysis and Transplant Registry. ANZDATA Registry Report 2005. Adelaide, South Australia, 2005. Available from: http://www.anzdata. org.au/v1/annual_reports_download. Accessed: February, 2016.

11. Hattori S, Yosioka K, Honda M, Ito H, Japanese Society for Pediatric Nephrology. The 1998 report of the Japanese National Registry data on pediatric end-stage renal disease patients. Pediatr Nephrol. 2002 Jun;17(6):456-61. doi: 10.1007/s00467-002-0848-8.

12. KDIGO 2012 clinical practice guideline for the evaluation and management of chronic kidney disease. Kidney International supll. 2013;(1):163p. DOI:10.1038/kisup.2012. 